\title{
Struggles of Tamang children in achieving elementary education
}

\section{Sapana Adhikari}

\begin{abstract}
This paper explores on how Tamang children achieve elementary education along with their socioeconomic conditions. This study tries to assess the impact of living condition, home and surrounding environment, parental education, and economic condition of the family on elementary education of Tamangchildren of Dhankuta district, aged 6-14 of. Data were collected from 15 households, purposively selected, through interview and observation, and the thematic analysis was done employing qualitative research design. It was found that, of the total 18 children,27.27\% were non-enrolled, $24.14 \%$ drop-outs while $48.56 \%$ were continuing formal education. It was also found that the economic factors (poverty), family size, and home condition were the major struggle of the Tamang children in achieving elementary education. To combat with these issues income generation and poverty alleviation programs should be properly implemented; more job opportunities and shelters for the shelterless families are to be provided at low and affordable prices; and teachers and school authorities should make the parents aware about the importance of sending children regularly to school.
\end{abstract}

Keywords: Tamang children, elementary education, poverty, drop-out, unemployment Introduction

The word 'child' is defined variously. There is no any universal consensus regarding the definition of child because it is determined by various factors i.e. social, economic, cultural, political etc. Generally, adulthood is denoted by the legal age of voting, right to citizenship, age at entry into the armed force etc. The age below this, obviously, represents the status of being a minor or a child. The period of life span until getting proper maturity can be categorized as childhood. This is basically the case of developing countries, not the developed ones. United Nations has defined a child as a person under age of 18 and has also stated that it may be different according to national laws, rules and regulations. According to Nepalese legal provision, a child is defined as a minor of either sex below the age of 16 years (Children Act, 1992, Article 1).

Children should be cherished. Today's children are the future of society and leaders of the country and drivers of the coming generations, so they need special attention and care. This helps to enhance their potentialities that can contribute to the prosperity of the nation. . It is said that children are the pillars of the world and their overall development should be the most priority of every country. However, according to a joint data provided by UNICEF International Labour Organization (ILO) and World Bank 168 million children aged between5 to 17 remain worldwide.

A child means every human being below the age of 18 . According to the United Nations Convention on the Right of the Children (UNCRC, to the child, majority is attained earlier (article 
1). The Nepal Labour Act (1992) defines a child as a person below 14 years. The Children's Act (1992) defines a child as a person below 16 years. In many countries, a child tends to be defined in terms of age limits which vary with different activities. United Nations' Children's Fund (UNICEF) states that age limits are formal reflections of society judgment about the evolution of children's capabilities and responsibilities are the criteria (UNICEF, 1997).

UN- Habitat (2007) recognizes a household as a group of individual living under the same roof in the village area who lack one or more of the following: durable housing of a permanent nature that protects against extreme climate condition, sufficient living space-which means not more than three people sharing the same room, easy access to safe water in sufficient amounts at an affordable price, access to adequate sanitation in the form of a private or public toilet shared by a responsible number of people, security of tenure that prevents forced evictions. The under - privileged children residing in the Tamang households are deprived of various basic amenities that the non-Tamang children in general do enjoy, so they need special attention. With the rapid pace of urbanization, the face of the cities of Nepal is changing. Its consequences are not only uncontrolled population rises and unplanned settlement growth, but also the increase in the level of urban population and the sputtered settlements (UN, 2007).

Education plays a pivotal role in laying a foundation for the overall socio-economic development of any region. Education is considered as one of the principal means to foster a deeper and more harmonious form of human development and thereby to reduce poverty, exclusion, ignorance, oppression, and war (Dellor Commission, 1996). The social, economic and cultural development of a nation is an achievement which results largely on the educational attainment of its masses. Development theory in recent years has taken note of the importance of education as an index of development of a nation, and with its myriad positive effects on the functioning of a society. Hence, the outreach of education to every stratum of society is a subject of great concern (Dellor Commission, 1996)

It is in this context that I examined the state of elementary education of Tamang children in of Chaubise Gaupalika-3, Kurule, Tenupa of Dhankuta, which is upheld not only as an exemplary centre of learning and culture, but also as a district where unchecked urbanization has forced a great number of people to live in extremely squalid conditions, not having access to the basic amenities of life. Standing at this juncture it is absolutely necessary to understand and evaluate the present scenario of the Tamang children in regard to access, retention, and completion of elementary education of satisfactory quality. In this context I have tried to study the prevalent problems/struggle of non- enrollment, drop-out and irregular attendance of Tamang children of 6-14 year's age group of Kurule Tenupa of Dhankuta.The objectives of the study for this paper were to examine the struggle of Tamang children to achieve elementary education; andto explore the main causes of the Tamang children who are not attaining the elementary education. 


\section{Review of Literature}

In the relatively recent past, the country was ruled by the Shah Kings. Reforms in 1990 established a multi-party democracy within the framework of a constitutional monarchy. In 1996, the Nepal Communist Party (Maoist) launched a movement that capitalized on the growing dissatisfaction among the general population with the lack of reforms expected from a democratically elected government. Maoists ran a decade-long insurgency (1996-2006) against the ruling monarchy, which until then kept Nepal and Nepalese people in internal conflict and isolation. The people's mass movement of April 2006 in Nepal restored the parliament and the democratic process and initiated a peace movement that called for an end to the 10-year-long armed conflict (NDHS, 2011).

Children's or adolescents' participation in work that does not affect their health and personal development or interfere with their schooling is generally regarded as being something positive. This includes activities such as helping their parents care for the home and the family, assisting in a family business or earning pocket money outside school hours and during school holidays. It contributes to children's development and to the welfare of their families. It provides them with skills, attitudes and experience, and helps to prepare them to be useful and productive members of society during their adult life.

The Nepal Communist Party (Maoist) joined the democratic competition, and constituent assembly elections were held in April 2008 to devise a constitution to manage the root causes of the conflicts afflicting the nation (NDHS, 2011). Based on the experiences of these plans and as a follow up to the World Declaration on Education for All (EFA) in 1990, the country undertook planned interventions in the education sector with the introduction of the Basic and Primary Education Programmes I (1992-1999) and II (1999-2004). Furthermore, in line with the Dakar Framework for Action adopted in 2000, the country prepared the EFA National Plan of Action (2001-2015). Within its overall goals and objectives, the EFAP rogramme (2004-2009), and the Secondary Education Support Programme (2003-2009) were implemented (UNESCO, 2011:14). Since year 2009, the government of Nepal has begun to implement the School Sector Development Programme (SSDP), which aimed at restructuring school education with basic education; grade 1-8 and secondary education; grade 9-12 (MoE, 2016). In the school education system, primary and lower secondary levels have been integrated under basic education and the secondary and higher secondary levels are under the secondary education in the education system in the country(MoE, 2016).

A large number of schools are running the ECD (Early Childhood Development) programmes inside the school premises for children aged 3-4 years. The prescribed age group population for different levels of school education is 5-9 for primary, 10-12 for lower secondary and 13-14 for secondary schooling (MoE, 2011). However, a large number of children enroll in school at later years or after 5 which shows age variation among children studying at the same level. The 
majority of schools in the country include primary level (1-5), i.e. most of the lower secondary, secondary and higher secondary schools operate the primary level. Schools in Nepal are categorized into four types: community-aided; fully supported by the government for teachers' salary and other expenses, and community-managed. Childhood is the formative stage of human life. The development of the country depends upon the development of children. Child labour is the mark of disgrace for society. The world of tomorrow will be happy and a comfortable place for man to live in only if the child population of today is endowed with good health both mentally and physically sound children today (MoE, 2011).

Instead of the improvement in the situation, the present condition of Nepali children is far from satisfactory. Many children are forced to work in different and hazardous conditions simply to sustain their own lives and that of their family. The root cause of child labour is serving by acute poverty. However, a number of other factors also contribute; lack of access to education for children, employer-worker relationship in rural areas, rural urban migration, family problems such as, violence or significant change in the family structured caused by death or remarriage of a parents, lack of education of parents and so on. Nepal is one of the poorest countries with GNI PPP per capita income \$2313(PRB, 2015). According to International Poverty Measures; 38 percent of Nepalese people earn less than US \$1 per day, resulting in increasing hunger, disease, illiterate, and unemployment (World Bank, 2010).

\section{Methodology}

This study was cross-sectional and descriptive. It focused on the struggle of Tamang children in Kurule, Tenupa of Dhankuta district. The nature of data is primary as well as secondary. The survey was conducted through a semi-structured interview. The individual questionnaires (mixed method) were administered among the the struggling Tamang childrenalong with their demographic and socio-economic characteristics. There were live question answer sessions during the face-to -face interview and observation. The researcher took information about those Tamang children who are struggling for elementary education. I selected 18 respondents of 15 households of age groups 6-14 years and used the purposive sampling method (non- probability sampling). The researcher selected purposively 18 respondents struggling for achieving elementary education. The completed questionnaires were entered into the computer after editing and loading. Finally, latest developed SPSS program was used to compute the data. Frequency distribution and interpretation are the main output of the analysis.

\section{Results and Discussion}

This section briefly presents the interaction between the different factors and formal education of the Tamang children. It is divided into the following headings:

\section{Socio-Economic Condition of the Tamang children Demographic structure}

It was found that almost $90 \%$ families (9 families out of 10 ) were nuclear with an average family size consisting of 5 members. Out of the total number of households taken for the study, it 
was found that, almost $40 \%$ families (4 families) were migrated from different parts of Dhankuta district, especially from neighboring Village Development Committee like Chaubise Rural Municipality, ward no 3,Kurule Tenupa. The earlier as well as present studies have recognized that adequate, safe and secured housing is another important problem area that still persists among the Tamang children. Most of the houses have been found made up of mud, soil and blocks with Zink (Jasta Pata) roof; no separate kitchen or closed bathroom but one common latrine which was mostly dirty and unhygienic. Dirty water over flowing through broken or cracked popes spreads foul smell all around. None of the Tamang children owned any private room. At the entrance of each room utensils, cooking materials, buckets and drums (either filled or empty) were kept. Used utensils with stale left-over foods and even garbage were found to be heaped here and there which got scattered by street dogs and cats. This resulted in spreads of foul rotten smell.

\section{Parental occupation, income and education of the Tamang families}

It was found that majority of the head of the families were engaged in elementary occupations in which the income was not only low but also uncertain and depended upon availability of work. They were porters, sweepers, daily wage labourers, domestic helpers and so on. Nearly $20 \%$ heads of the families were not engaged in any economic activities either due to old age, illness or because of alcohol addiction.

The monthly income of the total number of households taken for this study was broadly classified into three groups as: i) not more than Rs. 3000 ii) between Rs. 3001 and Rs. 5000, and iii) more than Rs. 5000. It was found that almost $30 \%$ belonged to the first category. About $20 \%$ belonged to the second group and $50 \%$ belonged to the third group.

It was found that of the total 18 children, $27.27 \%$ were non-enrolled, $24.14 \%$ were dropout while $48.56 \%$ were reading or continuing education. Net Enrollment Ratio at elementary education level was found to be $72.73 \%$. Regarding the parental educational status of these children, it was found that more mothers (55.97\%) than fathers $(44.71 \%)$ were illiterate. Almost an equal percentage of parents $(26 \%)$ reported that they could only write their names and failed to recall how far or up to which class they had exactly studied in formal school.

\section{Struggle of Tamang Children in Achieving Elementary Education}

Among various problems/struggles faced by the slum children in getting elementary education most significant were from a poor economic condition (poverty) of the family, unfavorable home condition and surrounding environment, large family size, poor parental education, poor health, poor living condition and unstable occupation of parents. Out of them, the major struggles or problems are discussed below.

\section{Poor economic condition of the family}

Poverty is simply understood as a condition in which a person is lacking in the basic needs like food, clothes, shelter and safe drinking water (Chamber, 1987). According to her, it is the condition of excluding access to basic human resources like education, health freedom and 
opportunities. Poverty may also be understood as an aspect of unequal social status, inequitable social relationship, experienced as social exclusion, dependency, and diminished capacity to participate or develop meaningful connection with other people in society (Silver, 1996). Village poverty is a multi-dimensional phenomenon. The poor people in a village live with many deprivations. Their daily challenges may include limited access to employment opportunities and income, inadequate and insecure housing and services, violent and unhealthy environments, little or no social protection mechanisms, and limited access to adequate health and educational opportunities.

\section{Large family size}

A large family size implies a higher dependency ratio. In a family consisting of father, mother and three or four children of school age, where father is the only earning member, working in an unorganized sector with poor and unstable income and where all other family members are economically dependent on him. Then meeting the bare basic necessities becomes quite a tough job. In such a situation, the chance of providing elementary education to their children or even helping them to continue their studies gets affected.

\section{Unfavorable home condition and surrounding environment}

Most houses in the community were found made up of mud, soil and blocks. Such houses included small single dark, damp, rooms without proper ventilation provision to serve them for multi-purpose activities i.e. living, dining, cooking, sleeping, storing, cleaning, washing, bathing etc. A peaceful environment for concentrating and studying at home was almost missing. The entire surrounding environment was found to be dirty, unhygienic and susceptible to various diseases like dysentery, asthma, respiratory infection and so on.

A small room where bunk-like arrangement has been made to accommodate all family members and their belonging- bedding, clothes, utensils, buckets, drums, cooking ingredients and whatever else they possessed. In such a small room up to five members resided. Different activities were carried on simultaneously in the room, like chatting, cooking, listening to music, watching television, cutting vegetables, grinding spices and so on. Such conditions are not at all favorable for studying at home.

Some of the male members were addicted to alcohol or gambling, thus spending most of the money from whatever little they earned on depriving the basic necessities of the other family members. Alcohol was consumed openly. Under the feats of alcohol, quarrelling using abusive and slang language, beating wife and children was found as a common daily affair in almost every household. Children very naturally and spontaneously got accustomed with, learned and started using such language and developed a violent and hostile attitude towards others, which were commonly reflected in their behavior with their sibling, playmates and classmates.

\section{Measures Suggested for Reducing Struggle of the Tamang Children}

During an interview, teachers said that parents who earned less money felt that they were 
more responsible to fulfill family demands like food and clothing and security. Parent's work pattern also shows low income of the family. Most of the respondents' fathers were unskilledleading to be either unemployed during different times or were pushed to work in unskilled professions such as wage labour. Children's mothers were unemployed and worked only during farming seasons. Largely the children's parents worked as daily wage labourers. As a result, they got little income which was not sufficient to cover every cost of the family needs. If the income level of the family was low, the children might be called on to add to the household's income, either through wage earning employment or taking on additional tasks to free up other household members for work. The production tended to be less due to the traditional methods of cultivation but required more human resources so that the children's life was so hard.

\section{Conclusion}

A number of factors were identified to be responsible for the Tamang children's struggle for achieving elementary education. The major ones were health, nature of occupation of the family, level of mother's education, per capita income of the family, living condition, home and surrounding environment, school's infrastructure had a positive impact. However in the Tamang area, life of people seemed insecure, unhygienic and unstable. The poor villagers have resided in the poor quality of houses with no facilities of pure drinking water, safe electricity, drainage, which led to poor health and poor educational achievements of their children. Therefore, more and more income generation and poverty alleviation programs should be properly implemented under a strict monitoring system of the government. More job opportunities are to be provided for wage earners. Their working hours and minimum wage have to be fixed in such a manner so that, on one hand, they would not be exploited and, on the other, they could meet their basic minimum necessities and lead a healthy life. To meet the problem of acute shortage of village housing, lack of adequate infrastructures and basic services, attempt should be made by the government to provide better shelter/housing facilities to these people at low and affordable prices so that they could have a decent living condition to control the problem of irregular attendance. Similarly, teachers and school authorities should make the parents aware about the importance of sending children regularly to school. Such activities would help to enhance the elementary education of the Tamang children.

\section{References}

Chamber, R. (1987). Rural development: Putting the last first. London; Longman.

Chugh, S., (2011). Dropout in secondary education: A study of children living in slums in Delhi. National University of Educational Planning and Administration. New Delhi: NUEPA MoE, (2011). Flash report 1, 2011-2012. Kathmandu: Ministry of Education.

NDHS, (2011). Nepal Demographic and Health Survey 2011. Kathmandu, Nepal: Ministry of Health and Population, New ERA, and Macro International Inc. Nepal's Interim Constitution (2007). Kathmandu: Government of Nepal. 
Nepal Kanun Kitab Bewastha Samiti, 1992, Children Act.Kathmandu: Nepal Kanun Kitab Bewastha Samiti.

Silver, H. (1996). Culture, politics and national discourse of the new urban poverty. E. Mingione (Ed.), Urban Poverty and the Underclass, Oxford: Blackwell

UN-Habitat (2007). Twenty first session of governing council, 16-20, April 2007, Slum dwellers to double by 2030 , Nairobi

UNESCO, (2011). A Study in primary school level children in Nepal. UNESCO

VDC Profile of Kurule Tenupa, 2016, Dankuta district.

\section{The Author}

Sapana Adhikari is a Lecturer at Mahendra Ratna Campus Tahachal Nepal. She has completed Master's Degree in Curriculum and Evaluation from Tribhuvan University. She is currently aPhD scholar in Education studies at Tribhuvan University. She has published some articles in national journals. She is interested in doing research on teaching learning practices at Basic level. 